The Role of Parent Educational Attainment in Parenting and Children's Development

Pamela E. Davis-Kean, University of Michigan

Lauren A. Tighe, Northwestern University

Nicholas E. Waters, University of Michigan

Paper accepted at Current Direction in Psychological Science on December 28, 2020

Author Note: Pamela E. Davis-Kean (Corresponding Author) ISR, University of Michigan, 426

Thompson Street, Ann Arbor, MI 48104-2321; pdakean@umich.edu. We would like to thank the Human Development and Quantitative Methods Lab at the University of Michigan for helpful comments on an earlier draft of this article.

Keywords: parent educational attainment, socioeconomic status, parenting, child development, educational inequalities 
The Role of Parent Educational Attainment in Parenting and Children's Development 


\begin{abstract}
Socioeconomic status (SES) — indexed via parent educational attainment, parent occupation, and family income - is a powerful predictor of children's developmental outcomes. Variations in these resources predict large academic disparities among children from different socioeconomic backgrounds that persist across the years of schooling, perpetuating educational inequalities over generations. In this article, we provide an overview of a model that has guided our approach to studying these influences, focusing particularly on parent educational attainment. Parents' educational attainment typically drives their occupations and income and is often used interchangeably with SES in research. We posit that parent educational attainment provides a foundation that supports children's academic success indirectly through parents' beliefs about and expectations for their children, as well as through the cognitive stimulation that parents provide in and outside of the home environment. We then expand this model to consider the intergenerational contributions and dynamic transactions within families that are important considerations for informing potential avenues for intervention.
\end{abstract}




\section{The Role of Parent Educational Attainment in Parenting and Children's Development}

The recent COVID-19 global pandemic has placed a spotlight on the implications of educating children outside the institution of schooling, including the inequalities that can be produced by moving education exclusively into the home environment (Kuhfeld \& Tarasawa, 2020). Although the achievement gap between different groups of students has been well documented for decades (Reardon, 2011), there are few, if any, interventions that have been successful in reducing this gap — especially the gap associated with socioeconomic status (SES). These disparities in achievement are present even before school entry (V. E. Lee \& Burkam, 2002), which suggests that socioeconomic resources assert their influence before schooling and in a context where there is likely a passive (i.e., genetic or biological) and active (e.g., via cognitively stimulating activities, day-care or preschool enrollment) transfer of skills taking place from one generation to the next. Given the importance of socioeconomic factors for children's language development (Hoff, 2003), academic success (Davis-Kean, 2005), and behavioral outcomes (Yeung et al., 2002), there is a growing interest in identifying and intervening on the pathways underlying associations between SES and children's development (Duncan et al., 2017). As Duncan and Magnuson (2003) pointed out, however, it is also important to understand how the various indicators of SES differentially relate to child outcomes.

\section{Indicators of Socioeconomic Status: Parent Educational Attainment and Family Income}

Oftentimes, the omnibus term socioeconomic status is used interchangeably with parent educational attainment and family income (occupation is rarely used in psychological studies; Davis-Kean et al., 2019). Although specific SES indicators do tend to be correlated, each reflects a different resource that benefits children in unique ways (Duncan \& Magnuson, 2003). Parent educational attainment, for example, is often a stronger predictor of parental beliefs and behaviors, 
whereas family income is more closely associated with the provision of material resources (DavisKean et al., 2019). Thus, some researchers argue that SES indicators should not be combined and that, instead, their influences should be considered independently (Duncan \& Magnuson, 2003). A growing number of studies have followed this practice, and accumulating evidence points to parent educational attainment as being the more powerful predictor of children's cognitive and academic outcomes (e.g., Davis-Kean, 2005; Tighe \& Davis-Kean, in press; Waters et al., 2021). Given this evidence, we first review the theories using SES as an important component of parenting behaviors and then focus our attention specifically on parent educational attainment and its relation to parental beliefs, parental behaviors, and child outcomes.

\section{Intergenerational Transfer of Resources Through Parenting}

Many studies have observed robust associations between parent educational attainment and children's academic development across the years of schooling (for a review, see Reardon, 2011). As noted previously, this suggests an intergenerational transfer of ability and knowledge through both biological and environmental pathways (Liu, 2018). The influence of the more passive biological pathways has recently received strong support from research using polygenic scores, which has indicated that $7 \%$ to $10 \%$ of cognitive outcomes can be attributed to genetic factors (J. J. Lee et al., 2018). In the case of the more active environmental pathways, this transfer is thought to be made through the beliefs, activities, and educational opportunities that parents provide for their children in and outside of the home. For example, Davis-Kean and Sexton (2009) found that these environmental pathways accounted for $19 \%$ to $30 \%$ of the variance in achievement across various racial and ethnic groups in a nationally representative sample in the United States. These pathways, as depicted in the intergenerational-transfer-of-socioeconomic-resources-model (see Fig. 1), are influenced by several socioeconomic factors: parent educational attainment, occupation 
(both employment and job prestige), and income, the first of which often drives the other two (Mirowsky \& Ross, 2003).

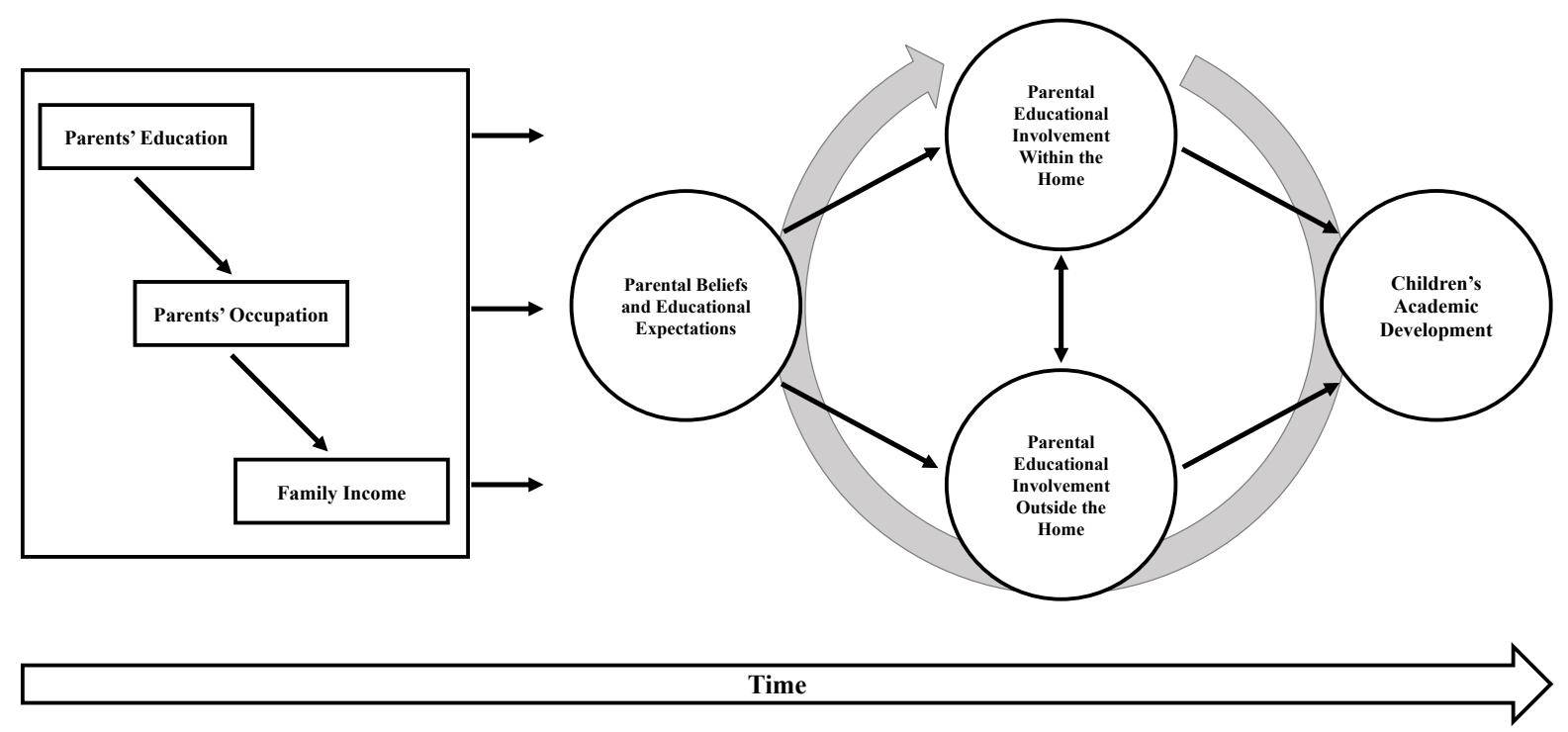

Figure 1. The Intergenerational-Transfer-of-Socioeconomic-Resources Model

This model is derived from a combination of important aspects of family-process models that link SES indicators to children's development. One such theoretical model, proposed by Harding et al. (2015), focuses on the underlying mechanisms that explain relations between maternal education and children's academic outcomes. It integrates several frameworksincluding human-capital, bioecological, and developmental-niche theories - to elucidate the complex processes that mold family life. This theory posits that with additional years of education, parents gain increased access to human (e.g., problem-solving ability), cultural (e.g., network connections), and social (e.g., high-achieving role models) capital, which jointly shape their parenting practices and their children's academic achievement (Harding et al., 2015). Indeed, there is empirical support for this theoretical perspective and the directional influence from parent educational attainment to parenting, which, in turn, influences child development. For instance, 
Magnuson and colleagues have demonstrated that pursuing additional schooling after the birth of a child, particularly for young mothers with initially low levels of education, yields improvements in the quality of their home environments, as well as their children's language and academic skills (Magnuson, 2007; Magnuson et al., 2009).

Other theories, including the family-stress and family-investment models, focus primarily on family income and its influence on parenting and child outcomes. First, the family-stress model proposes that economic hardship negatively affects parents' psychological well-being, which hinders their ability to be sensitive and nurturing with their children (Conger et al., 1992). Second, the family-investment model suggests that children from more economically advantaged families benefit from greater exposure to cognitively enriching resources and experiences (Haveman \& Wolfe, 1994). Although both theoretical models have garnered empirical support, investmentrelated processes have generally been found to be stronger predictors of children's achievement when the two models are tested simultaneously. Yeung and colleagues (2002), for example, demonstrated that relative to the warmth or the sensitivity parents displayed with their children, the investments they made in providing a stimulating learning environment were stronger predictors of their children's achievement. These findings have been corroborated by other research, including studies that have tested the equivalence of these models across various racial and ethnic groups in nationally representative samples (e.g., Davis-Kean, 2005; Davis-Kean \& Sexton, 2009). Thus, although both models provide an excellent foundation for understanding the social-causation perspective of socioeconomic influence, the family-investment model appears to hold greater explanatory power in relating family SES indicators-and, specifically, parent educational attainment—-to children's achievement outcomes. 


\section{Parenting Beliefs and Behaviors}

As posited in the intergenerational-transfer-of-socioeconomic-resources model, associations between socioeconomic indicators and children's academic development operate indirectly through the beliefs and behaviors of the parent. We have suggested that parent educational attainment, relative to the other indicators of SES, has a unique role in that it affords parents the capacity to seek out, identify, synthesize, and evaluate information on child-rearing and their child's well-being (Davis-Kean et al., 2019). These skills are then used to construct beliefs about and expectations of what children need to be successful in school, which in turn produce parental behaviors such as book reading, talking, playing, and modeling positive interactions. These behaviors enrich children's environments, subsequently leading to positive developmental outcomes (Davis-Kean et al., 2019). Multiple lines of research have shown these connections. Davis-Kean (2005), for example, documented that parents' beliefs about their children's development and learning vary by their level of educational attainment; more highly educated parents hold higher expectations for their children's academic success. Similarly, Suizzo and Stapleton (2007) found that mothers with higher levels of education have more ambitious expectations for their children's college attendance and completion.

Within the home environment, more highly educated parents tend to use more complex and rich language with their children (Hoff, 2003); engage in more verbal and nonverbal activities with their children (Suizzo \& Stapleton, 2007); spend more time with their children, and devote more of this time to developmentally appropriate activities (Kalil et al., 2012); provide their children with more educational resources (Davis-Kean, 2005); and spend a larger proportion of their budget on enrichment-related materials and experiences, including family trips, computers, books and magazines, school supplies, and recreational activities (Kaushal et al., 2011). 
Educational attainment is also related to the affective environment that parents provide within the home. For instance, highly educated mothers tend to be more emotionally responsive and have more positive and less hostile interactions with their children, compared with mothers with lower levels of education (Klebanov et al., 1994).

Parents' educational attainment is also related to the provision of enrichment activities outside the home environment. As children grow older, parents often become less involved in formal, school-based activities (e.g., attending parent-teacher conferences), but continue engaging in informal enrichment activities (Davis-Kean et al., 2019). For example, we found that lowincome, college-educated parents were more likely to take their child on educational outings, such as to libraries and museums, than were high-income, less-educated parents (Tighe \& Davis-Kean, in press). Further, these low-income, college-educated parents were often in teaching or administrative managerial positions. Although these occupations provide low wages, highly educated parents may be attracted to other occupational benefits that improve their family's wellbeing, including insurance, consistent schedules, job stability, and paid leave. These findings illustrate the distinct influence of higher educational attainment in families living in or near poverty. Whereas income is important for providing material resources, education provides the knowledge and belief system that enrichment activities are important for children's academic development, as well as the skills to promote this development.

\section{Transactional Influences}

Many existing theoretical models present directional arrows from parent to child, suggesting a unidirectional causal model to explain children's development. However, in reality, development is more accurately reflected as a transactional process in which parents and children influence one another over time (for a discussion, see Sameroff, 2009). For example, there is 
evidence for reciprocal associations between parents' academic involvement and children's reading achievement from early childhood to adolescence; greater academic involvement predicts more advanced reading skills and vice versa (Sy et al., 2013). These findings also extend to other aspects of development, as Bornstein et al. (2020) demonstrated that children's language development and the quality of their home learning environments are transactional and related to one another across the period from infancy to adolescence. Thus, the gray cyclical arrow included in the background of the intergenerational-transfer-of-socioeconomic-resources model (Fig. 1) is intended to highlight the importance of the dynamic and reciprocal nature of the parent-child relationship across development.

\section{Other Potential Influences}

In this article, we have reviewed the importance of family socioeconomic factors for constructing learning environments that promote children's academic development. Although there is an expansive literature on the many ways in which SES influences child development, we narrowed our focus to highlight the particularly strong role of parent educational attainment in shaping parenting and child achievement. However, there are other factors that are also important to consider. For example, the intergenerational-transfer-of-socioeconomic-resources model presents a two-generational approach (i.e., parent to child), explicitly indicating that the effect of SES is a multigenerational process. Research from sociology and economics suggests that investments across generations may be characterized as "accumulated wealth." Although wealth can be relatively distal to family processes, it is moderately correlated with other measures of SES and somewhat overlooked as a contributor to educational disparities, such as in college attendance (Killewald et al., 2017).

Further, we acknowledge that this discussion on the importance of parent educational 
attainment is situated in a more complex world than the one presented here. In particular, this review does not explicitly address the inextricable link between SES and race and ethnicity in the United States. García Coll and colleagues (1996) proposed a theoretical model of child development in which both social position and social stratification are at the core. They urged researchers to simultaneously incorporate multiple important sources of influence into mainstream models. Research by Davis-Kean and Sexton (2009) documented that there are important differences between racial and ethnic groups in how parental beliefs and behaviors promote children's achievement. For example, parents' expectations for educational success are more predictive of children's achievement among White American families than among other racial and ethnic groups in the United States. We encourage researchers to incorporate these and other potential influences by adapting and extending our model to more fully encompass the complex realities of children, parents, and families.

\section{Summary and Conclusions}

Research in psychology has traditionally focused on behavioral change at the individual level. This puts the onus on individuals to modify their behavior, even when the context surrounding them influences that behavior and is unchanging. We have referenced the achievement gap, but the "opportunity gap" reframes the discussion to focus on the contextual conditions (i.e., unequal and inequitable resources), rather than individual behaviors, that lead to large disparities in student achievement. In this article, we have reviewed some of the literature that supports strong and relatively stable associations between socioeconomic contexts and the construction of environments in which children develop. We have provided a conceptual process model that draws connections between at least two generations (i.e., parent and child), but have suggested that both biology and wealth also transfer from previous generations. Understanding the role that 
socioeconomic resources play in the outcomes for children and adults is helpful for considering which interventions may be useful at the individual level, and which may need more systematic changes at institutional or policy levels to produce changes in behavior.

Furthermore, public-policy initiatives to promote upward social mobility often target only one intervention mechanism, typically education or income. A long-term solution to addressing social mobility would be to increase parents' educational attainment, which traditionally leads to higher-paying jobs for parents, more income and resources, and improved outcomes for children (Duncan et al., 2017). But without social and financial supports, parents cannot simply quit their current job and enroll in school when they have familial responsibilities. Education can improve a family's long-term outcomes, but it will not pay bills and provide food, clothing, and medical necessities in the short term. An example of a policy solution designed to address these barriers is the ongoing CareerAdvance program, operated by the Community Action Project of Tulsa, Oklahoma (CAP Tulsa) and funded by federal Health Professions Opportunity Grants (Administration for Children and Families, U.S. Department of Health and Human Services).

CareerAdvance is a two-generation education program that targets parents and children from the same low-income families by offering tuition-free career training in the health-care sector to parents while their young children are enrolled in school. Parents in the program also receive a range of supportive services, including child care and financial assistance, peer cohorts, and coaching. CareerAdvance offers lifelong educational knowledge and skills to parents while also providing the necessary financial and social support in the short term. A recent quasi-experimental evaluation of CareerAdvance shows promising results for boosting parents' educational attainment (Chase-Lansdale et al., 2019) and children's attendance in Head Start (Sommer et al., 2020). CareerAdvance focuses on change at the individual family level, but results from evaluations of 
such programs have the potential to produce larger-scale changes at the policy level.

Bronfenbrenner (1977) first proposed that human development is the product of a dynamic interaction between an individual and the individual's environment. Our research program has expanded on this model to illustrate the important role that socioeconomic resources - specifically, parent educational attainment — play in creating a context of enrichment in families. We have noted that parental beliefs and behaviors are an important pathway for promoting development across generations and within individuals over time. We have also suggested expanding from static models of unidirectional transfer to more dynamic models that reflect the transactional nature of the parent-child relationship over time and within socioeconomic contexts. The influence of socioeconomic indicators on child development is important to understand, but so too is the broader association of these indicators with availability of resources for individuals to make changes for themselves and their families. Indeed, we often find that indicators of SES are more closely associated with children's achievement outcomes than are more proximal individual factors, such as cognitive skills like attention, working memory, and inhibition (Ahmed et al., 2019). We have provided a potential road map for future investigations aimed at providing a richer understanding of how socioeconomic contexts can shape children's academic development. 


\section{References}

Ahmed, S. F., Tang, S., Waters, N. E., \& Davis-Kean, P. E. (2019). Executive function and academic achievement: Longitudinal relations from early childhood to adolescence. Journal of Educational Psychology, 111(3), 446-458. https://doi.org/10.1037/edu0000296

Bornstein, M. H., Putnick, D. L., \& Esposito, G. (2020). Skill-experience transactions across development: Bidirectional relations between child core language and the child's home learning environment. Developmental Psychology, 56(10), 1842-1854. https://doi.org/10.1037/dev0001092

Bronfenbrenner, U. (1977). Toward an experimental ecology of human development. American Psychologist, 32(7), 513-531. https://doi.org/10.1037/0003-066X.32.7.513

Chase-Lansdale, P. L., Sabol, T. J., Sommer, T. E., Chor, E., Cooperman, A. W., Brooks-Gunn, J., Yoshikawa, H., King, C., \& Morris, A. (2019). Effects of a two-generation human capital program on low-income parents' education, employment, and psychological wellbeing. Journal of Family Psychology, 33(4), 433-443. https://doi.org/10.1037/fam0000517

Conger, R. D., Conger, K. J., Elder, G. H., Jr., Lorenz, F. O., Simons, R. L., \& Whitbeck, L. B. (1992). A family process model of economic hardship and adjustment of early adolescent boys. Child Development, 63(3), 526-541. https://doi.org/10.1111/j.1467-

\section{$\underline{8624.1992 . t b 01644 . \mathrm{X}}$}

Davis-Kean, P. E. (2005). The influence of parent education and family income on child achievement: The indirect role of parental expectations and the home environment. Journal of Family Psychology, 19(2), 294-304. https://doi.org/10.1037/0893- 
$\underline{3200.19 .2 .294}$

Davis-Kean, P. E., \& Sexton, H. R. (2009). Race differences in parental influences on child achievement: Multiple pathways to success. Merrill-Palmer Quarterly, 55(3), 285-318. https://doi.org/10.1353/mpq.0.0023

Davis-Kean, P. E., Tang, S., \& Waters, N. E. (2019). Parent education attainment and parenting. In M. H. Bornstein (Ed.), Handbook of parenting: Vol. 2. Biology and ecology of parenting (3rd ed., pp. 400-420). Routledge. https://doi.org/10.4324/9780429401459-12

Duncan, G. J., \& Magnuson, K. A. (2003). Off with Hollingshead: Socioeconomic resources, parenting, and child development. In M. H. Bornstein \& R. H. Bradley (Eds.), Socioeconomic status, parenting, and child development (pp. 83-106). Erlbaum.

Duncan, G. J., Magnuson, K., \& Votruba-Drzal, E. (2017). Moving beyond correlations in assessing the consequences of poverty. Annual Review of Psychology, 68, 413-434. https://doi.org/10.1146/annurev-psych-010416-044224

García Coll, C., Lamberty, G., Jenkins, R., McAdoo, H. P., Crnic, K., Wasik, B. H., \& Vázquez García, H. (1996). An integrative model for the study of developmental competencies in minority children. Child Development, 67(5), 1891-1914. https://doi.org/10.2307/1131600

Harding, J. F., Morris, P. A., \& Hughes, D. (2015). The relationship between maternal education and children's academic outcomes: A theoretical framework. Journal of Marriage and Family, 77(1), 60-76. https://doi.org/10.1111/jomf.12156

Haveman, R., \& Wolfe, B. (1994). Succeeding generations: On the effects of investments in children. Russell Sage Foundation.

Hoff, E. (2003). The specificity of environmental influence: Socioeconomic status affects early 
vocabulary development via maternal speech. Child Development, 74(5), 1368-1378. https://doi.org/10.1111/1467-8624.00612

Kalil, A., Ryan, R., \& Corey, M. (2012). Diverging destinies: Maternal education and the educational gradient in time with children. Demography, 49(4), 1361-1383. https://doi.org/10.1007/s13524-012-0129-5

Kaushal, N., Magnuson, K., \& Waldfogel, J. (2011). How is family income related to investments in children's learning? In G. J. Duncan \& R. J. Murnane (Eds.), Whither opportunity? Rising inequality, schools, and children's life chances (pp. 187-206). Russell Sage Foundation.

Killewald, A., Pfeffer, F. T., \& Schachner, J. N. (2017). Wealth inequality and accumulation. Annual Review of Sociology, 43, 379-404. https://doi.org/10.1146/annurev-soc-060116$\underline{053331}$

Klebanov, P. K., Brooks-Gunn, J., \& Duncan, G. J. (1994). Does neighborhood and family poverty affect mothers' parenting, mental health, and social support? Journal of Marriage and the Family, 56(2), 441-455. https://doi.org/10.2307/353111

Kuhfeld, M., \& Tarasawa, B. (2020). The COVID-19 slide: What summer learning loss can tell us about the potential impact of school closures on student academic achievement. NWEA.

Lee, J. J., Wedow, R., Okbay, A., Kong, E., Maghzian, O., Zacher, M., Nguyen-Viet, T. A., Bowers, P., Sidorenko, J., Karlsson Linnér, R., Fontana, M. A., Kundu, T., Lee, C., Li, H., Li, R., Royer, R., Timshel, P. N., Walters, R. K., Willoughby, E. A., . . Cesarini, D. (2018). Gene discovery and polygenic prediction from a genome-wide association study of educational attainment in 1.1 million individuals. Nature Genetics, 50(8), 1112-1121. 


\section{https://doi.org/10.1038/s41588-018-0147-3}

Lee, V. E., \& Burkam, D. T. (2002). Inequality at the starting gate: Social background differences in achievement as children begin school. Economic Policy Institute.

Liu, H. (2018). Social and genetic pathways in multigenerational transmission of educational attainment. American Sociological Review, 83(2), 278-304. https://doi.org/10.1177/0003122418759651

Magnuson, K. (2007). Maternal education and children's academic achievement during middle childhood. Developmental Psychology, 43(6), 1497-1512. https://doi.org/10.1037/0012$\underline{1649.43 .6 .1497}$

Magnuson, K. A., Sexton, H. R., Davis-Kean, P. E., \& Huston, A. C. (2009). Increases in maternal education and young children's language skills. Merrill-Palmer Quarterly, 55(3), 319-350. https://doi.org/10.1353/mpq.0.0024

Mirowsky, J., \& Ross, C. E. (2003). Education, social status, and health. Transaction Publishers.

Reardon, S. (2011). The widening academic achievement gap between the rich and the poor: New evidence and possible explanations. In G. J. Duncan \& R. J. Murnane (Eds.), Whither opportunity? Rising inequality, schools, and children's life chances (pp. 91116). Russell Sage Foundation.

Sameroff, A. J. (2009). The transactional model. In A. J. Sameroff(Ed.), The transactional model of development: How children and contexts shape each other (pp. 3-21). American Psychological Association.

Sommer, T. E., Schneider, W., Chor, E., Sabol, T. J., Chase-Lansdale, P. L., Brooks-Gunn, J., Yoshikawa, H., Morris, A., \& King, C. (2020). A two-generation education intervention and children's attendance in Head Start. Child Development, 91(6), 1916-1933. 
https://doi.org/10.1111/cdev.13397

Suizzo, M-A.., \& Stapleton, L. M. (2007). Home-based parental involvement in young children's education: Examining the effects of maternal education across U.S. ethnic groups. Educational Psychology, 27(4), 533-556. https://doi.org/10.1080/01443410601159936

Sy, S. R., Gottfried, A. W., \& Gottfried, A. E. (2013). A transactional model of parental involvement and children's achievement from early childhood through adolescence. Parenting: Science and Practice, 13(2), 133-152. https://doi.org/10.1080/15295192.2012.709155

Tighe, L. A., \& Davis-Kean, P. E. (in press). The influence of college education on children and parents from low-income families. Merrill-Palmer Quarterly.

Waters, N. E., Ahmed, S. F., Tang, S., Morrison, F. J., \& Davis-Kean, P. E. (2021). Pathways from socioeconomic status to early academic achievement: The role of specific executive functions. Early Childhood Research Quarterly, 54(1st Quarter), 321-331. https://doi.org/10.1016/j.ecresq.2020.09.008

Yeung, W. J., Linver, M. R., \& Brooks-Gunn, J. (2002). How money matters for young children's development: Parental investment and family processes. Child Development, 73(6), 1861-1879. https://doi.org/10.1111/1467-8624.t01-1-00511 


\section{Recommended Reading}

Conger, R. D., \& Donnellan, M. B. (2007). An interactionist perspective on the socioeconomic context of human development. Annual Review of Psychology, 58, 175-199. Provides a review of the theories that link socioeconomic indicators to family processes and the developing child.

Davis-Kean, P. E. (2005). (See References). Uses a nationally representative data set to examine how parent educational attainment and family income relate to children's achievement indirectly via parental beliefs and behaviors.

Duncan, G. J., \& Magnuson, K. A. (2003). (See References). Provides an overview of the importance of using individual indicators of socioeconomic status rather than a constructed composite variable like the Hollingshead Index.

Lareau, A. (2011). Unequal childhoods: Class, race, and family life, with an update a decade later. University of California Press. An ethnographic study of children growing up in different socioeconomic circumstances and how their early life experiences shape their transition into adulthood. 